\title{
A PEC N. 55/2016 e o Medo que dela Sobrevém: Agenciamentos, Disputas e Enquadramentos no Ativismo em HIV/Aids ${ }^{1}$
}

\author{
PEC N. 55/2016 and the Fear it Brings Up: Agency, Dispute \\ and Framework in the HIV/Aids Activism
}

Ricardo Andrade Coitinho Filho

Programa de Pós-Graduação em Antropologia, Universidade Federal Fluminense, Armação dos Búzios, Rio de Janeiro, Brasil

\section{RESUMO}

Que estratégias têm sido elaboradas no movimento social em HIV/Aids, frente ao estigma que ainda permeia as concepções sobre a doença e aos sujeitos a esta associados? Tomando como centralidade a questão anterior, este artigo propõe refletir sobre disputas internas relativas a redefinições de ações e demandas políticas no cenário brasileiro, pósgolpe de 2016, e seus desdobramentos na produção de um repertório ativista emergente. Parte-se da etnografia realizada com uma rede de jovens que vivem e/ou convivem com HIV/Aids na interseção com outros coletivos, em que se problematiza o alcance das ações realizadas em relação aos enquadramentos produzidos como demanda de reconhecimento. Num aspecto geral, as questões são discutidas a partir de noções geracionais e gramáticas morais, na tentativa de criar um escopo político que se pretende "de todos".

Palavras-chave: HIV/Aids, Estigma, Ativismo, Conflitos geracionais, Moralidades.

1 A pesquisa que originou este artigo teve financiamento da Capes, por meio de bolsa de doutorado. 


\title{
ABSTRACT
}

What strategies have been elaborated in the HIV/Aids social movement, considering the stigma and conceptions linked to the disease and individuals who are associated to it? Considering the question above, this article aims at reflecting about internal dispute related to redefinitions of the actions and political demand in the Brazilian scenario, after 2016 political coup, and its development on the emergent activist repertoire production. It has been used an ethnographic data conducted with young people who live with HIV/Aids in the intersection close to other groups, in which the outreach of accomplished actions in relation to produced framework as recognition demand are often discussed. In a general aspect, the discussion is supported by generational notions and moral compass in the attempt of creating a political scope that reaches "all individuals".

Keywords: HIV/Aids. Stigma. Activism. Generational Conflicts. Morality.

\section{INTRODUÇÃO}

\begin{abstract}
Ativismo (ou seria um "Desabafo"?)
Estava pensando [...]. Ser ativista não significa, necessariamente, sair por aí levantando bandeiras ou declarando publicamente sua sorologia nem suas ideias. Muitas vezes o grande exemplo pode ser dado num momento de silêncio representado por determinada atitude, que pode repercutir muito mais, ter maior impacto e transformar para sempre a reação do outro. Estou falando de atitudes sim, ativismo ao longo dos anos, amadurecimento pessoal e ajuda para um amadurecimento coletivo. Lutar pelos direitos, caso estes sejam desrespeitados, significa mostrar as regras a quem desrespeitou, citar as leis e os motivos pelos quais se luta. Para que isso aconteça, o conhecimento sobre o assunto é fundamental, assim como saber os caminhos, locais e instituições preparados para dar suporte técnico e até mesmo legal.

Conquistar respeito depende do posicionamento diante da vida, do mundo e do próprio respeito a si mesmo e ao outro. Integridade, honestidade, honra, profissionalismo conquistam pessoas, conquistam respeito. Independe de sexo, sexualidade, raça, cor da pele, nível socioeconômico.

Observem algumas pessoas públicas. Alguns artistas se tornam verdadeiros ídolos independentemente de raça ou sexualidade. São pessoas que representam um papel importante na sociedade e são assim "ativistas" sem que isso seja oficial. Um paciente portador do HIV que toma diariamente seus medicamentos, que sabe o que precisa conhecer sobre a infecção, que conhece as medidas preventivas e explica aos amigos quando necessário, que conversa com um amigo que precisa de ajuda ao acabar de receber seu diagnóstico, que discute sobre novos avanços do tratamento, que não aceita receber um "não" se faltar seus medicamentos nos postos, faz muito bem seu papel como
\end{abstract}


ativista sem saber e segue seu caminho. Amadurece a cada dia. Transforma o mundo ao se tornar melhor para si mesmo. Não precisa ir a nenhum lugar "lutar por direitos". Pode seguir seu caminho em busca de crescimento pessoal e profissional. Já está fazendo por ele e por muitos.

Complicado é saber que alguns "ativistas" são os primeiros a parar de tomar os remédios e adoecem por Aids, correndo real risco de morte. Como diz a letra daquela música do Nando Reis (Relicário): “o mundo está ao contrário e ninguém reparou".

O texto anterior reflete tensionamentos e disputas sobre a visibilização de demandas públicas e construção de agendas políticas. Foi publicado em uma rede social num contexto de fomento de discussões sobre ativismo em HIV/Aids² e, devido à possibilidade de interlocução, tomado como mote de uma série de questionamentos. A reflexão girou em torno do alcance entre atuação individual e coletiva.

Tomo como eixo de reflexão os desdobramentos que partiram desta discussão e outros acionados em razão desta, dentro do contexto da pesquisa realizada no doutoramento. Isto é, na forma como os jovens que vivem com HIV/Aids têm mobilizado importantes temas a partir de suas experiências interseccionadas (CRENSHAW, 1991, 2002; BRAH, 2006; MCCLINTOCK, 2010). Isso tem provocado importantes "deslocamentos" na produção do ativismo em HIV/ Aids e rearticulado pautas e "negociações" a partir de diferentes regimes de visibilidade. Suas articulações são instituídas a partir da identificação como participantes da Rede de Jovens $+R J$.

Tal como propõe Peirano (2014), tomo como problematização "estranhamentos" que não cabem na fixidez de um campo que "tem momento certo para começar e acabar" (PEIRANO, 2014, p. 379), mas antes pelo que é constituído reflexivamente na interação teoria/empiria.

O texto "Ativismo (ou seria um 'Desabafo'?)”, denota em si as controvérsias inerentes à proposição da atuação em movimentos sociais e às tensões que são produzidas em meio à produção de um repertório político que pretende representar todos. Tais controvérsias e as disputas que giram em torno delas — com reflexos na dimensão política das identidades — serão tomadas como centrais para o desenvolvimento da discussão que ora se propõe.

Enveredar a discussão pela problemática em torno do que move pessoas ao ativismo poderia levar a pressupor que esta é uma condição final daqueles que estão inseridos na Rede de Jovens $+R J$. Em vez disso, proponho as seguintes questões: "De que modo os participantes que se identificam como ativistas têm atribuído sentido a esta forma de atuação? Ao experienciá-la, em que medida, refletem o processo de constituição das identidades sorológicas? Há relação

2 Os grupos de interação virtual têm sido utilizados como forma de "aproximar" pessoas, dúvidas e experiências, por meio de um contato que se propõe "de mais fácil acesso". 
entre a definição de estratégias de agenciamentos políticos e táticas de vivência cotidiana, num contexto marcado pela permanência do estigma associado ao HIV/Aids?”, E por fim: “Qual é o lugar que as experienciações sorológicas interseccionadas a outros marcadores de diferenciação ocupam neste cenário?”.

\section{O MOVIMENTO HIV/AIDS E SUAS DIMENSÕES DE AÇÃO SOCIAL}

A atuação da rede - como é conhecida a Rede de Jovens + RJ — configura-se entre ações de ajuda mútua e ativismo, e tem sido operacionalizada a partir do princípio da solidariedade. Isso se dá em virtude do que autores como Parker (1994a, 1994b e 1997) e Galvão (2000) retratam acerca das dimensões da "resposta coletiva à Aids", historicamente insurgida com a aparição dos grupos sociais que dialogavam com agentes e instâncias do Estado.

Estes grupos surgiram como decorrência do processo de institucionalização de pessoas em torno de ações de ativismo e ajuda mútua, e valeram-se da acusação de uma morosidade de atuação do poder público para a construção de uma política de enfrentamento à Aids. $\mathrm{Na}$ primeira década, surgiram importantes instituições cuja atuação se deu no eixo Rio-São Paulo, como o Grupo de Apoio à Prevenção à AIDS (GAPA) em 1985, a Associação Brasileira Interdisciplinar de AIDS (ABIA) em 1986, e o Grupo Pela VIDDA (Valorização, Integração e Dignidade do Doente de Aids) em 1989.

Essas entidades tiveram um papel fundamental para a construção de uma "resposta brasileira", cada vez mais marcada por contradições socioeconômicas de implicação na saúde. Elas atuaram também na promoção de ações de informação e prevenção e produziram novos significados sobre práticas sexuais a partir da noção sobre "sexo seguro". A produção do cartaz "Transe numa boa" (GAPA/1985) e a introdução do preservativo peniano (camisinha) - cujas investidas se deram a partir de espaços de sociabilidade gay como estratégia preventiva, a exemplo das ações de grupos gays norte-americanos — refletem os esforços destes atores (cf. PINHEIRO, 2015).

Também foram redefinidas demandas que se propõem coletivas na esteira das transformações epidemiológicas e sociais, que foram ocasionadas pelos adventos científicos no campo do HIV/aids. Destaca-se a introdução da Terapia Antirretroviral como política de saúde do Sistema Único de Saúde, em 1996. Dentre outros fatores, ressignificou-se a concepção sobre vida e morte de crianças nascidas com HIV, pela transmissão vertical (de mãe para filho). 
Conforme delineado por Cunha (2018), a emergência da categoria "Jovem Vivendo com HIV/Aids" e a consequente construção de políticas públicas para este segmento se dá neste contexto. A autora reconstrói o processo de criação e fortalecimento ao gradual desmembramento da Rede Nacional de Adolescentes e Jovens Vivendo com HIV/Aids, a partir da etnografia realizada entre 2006 e 2015. A regionalização das redes foi um desdobramento do IV Encontro Nacional de Adolescentes e Jovens Vivendo com HIV/Aids, em 2009, que impulsionou a criação de redes estaduais e regionais, como a do Rio de Janeiro.

Esse processo partiu do ideal de fortalecimento de uma nova geração de ativistas que dariam continuidade às ações do movimento de Aids à percepção e temor de tutela e assunção das agendas institucionais de agentes do governo e da UNAIDS ${ }^{3}$. A articulação destes atores institucionais às diferenças que se produziam no interior deste segmento foi fundamental para os contornos políticos que passaram a ser redefinidos na rede. Além da criação de um formato de ações voltadas para os jovens, outro importante fato ocorrido em decorrência do fomento à formação política dos jovens vivendo e da atuação das redes foi a introdução em espaços (cadeiras) de decisão voltados para as esferas políticas de saúde e de juventude (CUNHA, 2018).

Disputas internas foram travadas em torno da centralização e descentralização como modelo de representação e da participação de pessoas soronegativas e adultos. Esses critérios assumiram diferentes significados ao longo da atuação da rede nacional. No Rio de Janeiro, a rede apoiou e participou da integração às demais redes num modelo centralizado até o momento da cisão. Pessoas adultas e soronegativas poderiam participar, mas seriam limitados a alguns espaços (inclusive virtuais) e à participação política.

Neste aspecto, a rede de jovens do Rio de Janeiro era constituída pela participação de três grupos: jovens vivendo (que tinham diagnóstico positivo), jovens convivendo (diagnóstico negativo, com relação de proximidade com o primeiro grupo) e facilitadores (pessoas adultas, com ou sem diagnóstico positivo, cuja atuação implique diretamente ações promovidas pela rede). A principal diferença entre estas categorias era a forma de participação política, na qual apenas os primeiros tinham direito a voto, ocupação de liderança ${ }^{4}$ e participação em determinados espaços dedicados a jovens vivendo. A fala é entendida como destinada a todos.

Inicialmente a atuação estava fixada em ações coerentes aos diferentes espaços que se produziam: o "acolhimento", realizado mensalmente em locais públicos previamente definidos;

\footnotetext{
3 Programa Conjunto das Nações Unidas sobre HIV/Aids.

4 Essa questão assumirá diferentes interpretações, conforme o "entendimento" dos jovens que ocuparam a liderança. Em dado momento, um jovem soronegativo, participante da rede pela convivência afetivo/sexual com outro jovem soropositivo, chegou a ser eleito como coordenador.
} 
e a "incidência política", cuja periodicidade era definida segundo as reformulações do Estatuto. No entanto, questões que não tratam especificamente sobre HIV/Aids, mas compreendidas como "atravessamentos", borraram a rigidez dessas definições estabelecidas previamente. A circulação e ocupação dos jovens em espaços de outros coletivos do movimento social em HIV/ Aids, outros coletivos identitários, grupos de pesquisa e coletivos universitários e articulações políticas partidárias oportunizaram redefinições e reordenamentos internos ${ }^{5}$. As ações também foram movidas rumo a maior diversificação em termos de estratégias ${ }^{6}$, que discutiremos mais à frente, e em relação ao alargamento da noção sobre "viver com HIV/Aids".

Assim como identificado por Aguião (2014) e Carvalho e Carrara (2015), compreendo a emergência e/ou novas formas de participação social nestes espaços de interação socio-estatal como características das políticas de governo Lula/Dilma (PT). A abertura propiciada por esta nova forma de governo foi fundamental na articulação de convenções, reconfigurações e nexos relativos à expansão do escopo, em conteúdo e forma, do ativismo em HIV/Aids. Inclusive, será o rompimento a este modo de governo, a partir do golpe ${ }^{7}$ de 2016, que engendrará instabilidades nos segmentos do movimento de Aids e, consequentemente, a busca pelo consenso de uma nova agenda e formato de atuação ativista.

Uma das principais provocações trazidas para o interior do grupo foi a vocalização das experiências próprias, conforme a dinâmica já preexistente, mas a partir de articulações em relação à classe, raça, geração, gênero e sexualidade. Tal fato provocou importantes mudanças na construção dos repertórios políticos e exigiu o esforço de estratégias concomitantes às mais visibilizadas, na busca por evidenciar a relevância da introdução destas questões.

Em virtude dessa hibridez sobre a qual a rede se articula, os membros pertencentes a ela produzem formas de ação social coadunada às lógicas de dinamização da identidade sorológica, que relacionalmente se constroem. Na tessitura das ações, a solidariedade - que opera como um princípio desde a criação dos movimentos HIV/Aids — tem sido ressignificada por ações de reciprocidade.

Conforme destaca Cunha $(2011,2014)$, o surgimento do Jovem Vivendo com HIV/Aids

5 Tal configuração do movimento HIV/Aids em torno de iniciativas de mobilização se relaciona a de outros movimentos sociais, como o movimento negro, feminista e LGBTQI+ articulando afirmações identitárias e reconhecimento de direitos.

$6 \mathrm{O}$ uso da internet como forma de mobilização tem sido utilizado, inclusive, com "grupos secretos" de discussão. No entanto, não nos ateremos na problematização dessa esfera de atuação neste momento.

7 Utilizo esta noção ao longo do texto como forma de demarcar uma nova disposição que será instituída a partir deste advento no sistema de governo brasileiro. Seu uso analítico permite compreender a circunstância nevrálgica de rupturas e desinstitucionalização de políticas sociais, como a propositura e promulgação da $\operatorname{PEC~n}^{\circ}$ 55/2016. 
reflete um processo no qual este sujeito, que passa a ser lido dentro de estruturas epidemiológicas, políticas e morais, também é compreendido como importante ator na redefinição das políticas de Aids (BASTOS, 2002). A intencionalidade na introdução deste sujeito, já apresentada por Cunha $(2011,2014)$ e que faz referência aos dados da pesquisa que venho desenvolvendo, é o de favorecer a reprodução de sensibilidades "entre pares", por meio da atuação em "papéis sociais" (GOFFMAN, 1975) historicamente situados.

As ações empregadas variam desde uma visita a alguém adoecido por Aids ou que esteja apresentando sentimentos de sofrimento relacionadas ao convívio com o diagnóstico, empréstimos de comprimido da terapia antirretroviral para alguém que eventualmente tenha ficado sem, uma conversa "para levantar o astral", até a publicização da própria trajetória como "modelo positivado de um HIV possível". São oportunidades como estas que, paradoxalmente, põem em suspeição e, ao mesmo tempo, legitimam um discurso preventivo biomédico oficial. $\mathrm{Na}$ experienciação prática, favorece na produção modelar dos jovens como sujeitos político-morais (CUNHA, 2014).

Como compartilhamento de um dom (MAUSS, 2003) ${ }^{8}$, essas ações visam a atender a uma dimensão moral daquele que outrora fora "ajudado" a "ajudar" alguém, transmitindo, assim, o dom recebido". Coadunadas, tais ações operam na constituição da própria rede em suas distintas esferas, conforme Godbout (1999) pode compreender, ao se atentar às formas como a dádiva tem sido dimensionada no contexto da "modernidade" 10 . Em sua discussão, indica-se que, embora os sujeitos se constituam socialmente de modo desigual, há sempre um valor simbólico vinculado às relações sociais. $\mathrm{O}$ autor contribui para pensar a atuação política dos atuais grupos de ajuda mútua, no que se refere à constituição de dádivas, em que a solidariedade circula reciprocamente como um valor.

Também contribui para a discussão a revisitação dos estudos sobre movimentos sociais, feita por Daniel Cefai (2005, 2009), a partir de uma perspectiva pragmática da ação coletiva.

8 A concepção de trocas-dádiva em Marcel Mauss (2003) envolve múltiplas dimensões e não se dá entre indivíduos, mas entre coletividades que se obrigam reciprocamente. As trocas representam um caráter obrigatório de dar, receber e retribuir entre os respectivos membros de uma transação.

9 Essa dimensão moral se prevalece, mesmo considerando situações adversas em relação ao ativismo e às vicissitudes referentes ao processo de juvenilização da Aids, como também questões sobre namoros e trocas de parceiros sexuais dentro do próprio grupo.

10 Para o autor, a ideia de que a dádiva não existe entre as pessoas nas sociedades modernas é um mito construído a partir de noções de utilitarismo e individualismo. Para isso, o autor repensa a ideia de "obrigação de dar e retribuir" não como uma imposição, mas sim como inerente ao fenômeno da construção de relações humanas. Nesse processo, o Estado, em relação com o mercado, liberaria o indivíduo das obrigações ligadas às relações sociais, substituindo-as por certos tipos de serviços ou de bens. Para uma análise mais detalhada, ver Godbout (1999). 
Vale destacar, dentre estas, as que se articulam com o contexto etnográfico e que serão tomadas como base para o desenvolvimento analítico proposto.

Destaca-se, nesta perspectiva, o modo como identidades são operadas a partir da noção de cidadania, na forma como "a questão social tornou-se o lugar central das contradições do novo mundo que emerge" (CEFAI, 2005, p. 150). Em relação à rede de jovens, o uso de identidades clínicas e políticas, como ser "soropositivo" e "pessoa vivendo", respectivamente, evidenciam o modo como esses sujeitos operam segundo uma gramática do "direito à saúde", por exemplo. Entremeadas de contradições, essas identidades são produzidas em meio a conflitos e disputas. Ao evidenciarem suas experiências interseccionadas, avançam em pôr em suspenso uma noção única destas identidades — a do "jovem vivendo com HIV/Aids" —, complexificando as próprias políticas de saúde.

Por isso, é necessário problematizar a dinamização das atividades que geram conformações identitárias. Essa questão é de extrema relevância, pois evidencia que os atores coletivos são reflexos de construção e agenciamentos, e não sujeitos previamente constituídos.

[...] quando "indivíduos" se fazem "consumidores", "habitantes" ou "cidadãos", "mulheres", "desempregados" ou "imigrantes ilegais", por meio de suas denúncias e reivindicações, devem prestar contas do que fazem, de por que o fazem e em vista do que o fazem. Certo número de ativistas trabalhou na constituição de uma linguagem comum, na enunciação de repertórios de identidades coletivas e na confecção de modos de engajamento público (CEFAI, 2009, p. 27).

O autor toma, como referência à sua argumentação, o modo como feministas buscaram, a partir das denúncias reclamadas pelas mulheres numa primeira fase do movimento, reordenar novos universos. Isto é, as arenas públicas são organizadas a partir da construção de sujeitos que tornam suas experiências relacionadas a uma ação coletiva em comum. Conforme já destacado, os encontros de "acolhimento", oportunizados mensalmente, são utilizados como espaços privilegiados para a produção de narrativas e emoções coletivizadas (cf. COITINHO FILHO, 2018) e passaram a trazer, por meio das reordenações, um valor político da "perspectiva jovem". A idiossincrasia proposta evidenciava a substanciosa diferença entre os contextos de inserção dos ativistas na política de Aids, como veremos a seguir.

O “ouvir" e o "falar", ainda que vinculado à manutenção do projeto moral de positivação da sorologia, característico de um primeiro momento de atuação dos coletivos que se organizavam em torno da pauta da Aids, também evidenciou a correlação a dimensões políticas. Alguns dos fatores que favoreceram estas mudanças foram: os tensionamentos e as controvérsias dos 
jovens com outros segmentos do movimento de Aids; o rompimento da rede do Rio de Janeiro com a de outros estados e a nacional; e as disputas pelo "protagonismo jovem" no interior da própria rede. Ou seja, houve cooperação para forjar uma "cara própria" da rede do Rio de Janeiro, agora Rede Jovem Rio+.

A inserção de alguns membros em espaços dedicados à garantia dos direitos das Pessoas Vivendo com HIV/Aids ${ }^{11}$ também contribuiu para rearticular ações e redefinir pautas que impactam diretamente no modo como experienciam cotidianamente a sorologia e passaram a tomá-la como fator político. A circulação por setores e instâncias estatais materializam a busca por reconhecimento de suas demandas e participação em (re)formulação de políticas públicas. Entre essas instâncias estatais, citam-se: postos de saúde, conselho gestor municipal e estadual, centros de testagens e acolhimento, como também a programas internacionais ligados a OMS e a UNAIDS, programas federais, comissões legislativas.

Num outro momento da minha pesquisa, ao acompanhar um interlocutor na sua consulta de rotina, ouvi a assistente social da unidade convocá-lo para ir à reunião do conselho municipal. Ela atua em parceria com a rede e enfatizou a relevância da participação de pessoas vivendo naquele espaço, pois segundo ela "assim como tá acontecendo com os conselhos tutelares, pessoas com mentalidade conservadora podem vir a assumir espaços de decisão. Eles estão participando ativamente das reuniões e a eleição pode ser muito ruim para nossa política de Aids".

Esses modos de participação produzem uma plataforma de reivindicações, a partir de alianças e disputas pela ocupação de espaços de decisão. Semelhante aos dados analisados por Aguião (2014), a estratégia empregada relaciona a visibilização de demandas de certos sujeitos à busca pelo reconhecimento do Estado e seu poder em conferir legitimidade sobre o que se pleiteia.

Abers e Von Bulon (2011) atentam, nesse processo, como ações sociais são enveredadas na busca por políticas públicas, no modo em que "se mobilizam em prol de mudanças nos processos de tomada de decisão estatal, demandando a inclusão da sociedade civil em novos espaços participativos" (ibid, p. 65).

11 Esta categoria foi criada pelos sujeitos participantes de um encontro de ONGS-Aids, no Rio de Janeiro, em 1994, como substituição das categorias "aidético" e "soropositivo". Para além da modificação dos significados de cunho moral e clínico, respectivamente, a categoria Pessoa Vivendo com HIV/Aids atendia a uma perspectiva de compreensão do sujeito que vive com HIV/Aids como uma pessoa na sua integralidade, ao invés de reduzida a um vírus e/ou a uma condição de vetor epidemiológico. Identificar-se como Pessoa Vivendo remete a uma dimensão política e social. Neste mesmo contexto mencionado, criou-se a Rede Nacional de Pessoas Vivendo com HIV/ Aids, entendida como movimento social que corroboraria para o fortalecimento das "pessoas vivendo", por meio de duas frentes principais: ações de enfrentamento ao estigma e discriminação e na instrumentalização dos seus membros para ocupar espaços dedicados a decisões sobre saúde e políticas de governo, além do ativismo. 
A discussão e aprovação em torno da PEC n. 55 (241) ${ }^{12}$, em 2016, representou um primeiro momento de rompimento deste modelo participativo da sociedade civil na esfera burocrática, pós-governo petista (2003 — agosto de 2016), e de regulação dos direitos à saúde aos que fazem uso de políticas de Estado. No cenário do ativismo em HIV/Aids, esta política foi recebida com angústia, preocupação e medo em virtude dos "retrocessos ligados aos direitos e políticas da pessoa vivendo com HIV/Aids".

A matéria de que tratou esta Emenda Constitucional delineou medidas para o congelamento de gastos públicos, com relevante impacto nas pastas da educação e da saúde, entre outros setores, sob a alegação de superação da crise econômica. A previsão foi a de duração de vinte anos e pode haver alteração após avaliação dos dez anos iniciais de execução.

Num dado contexto de discussão entre diferentes segmentos do movimento de Aids, realizado na região central do Rio de Janeiro, em outubro de 2016, uma mulher que se identificou como ativista e vinculada ao movimento nacional de Pessoas Vivendo com HIV/Aids (PVHA) levantou a seguinte questão:

\begin{abstract}
"Pense nos desafios que temos hoje em relação a medicamentos com maior eficácia e menos efeitos colaterais patenteados. Agora imaginem congelarem essa nossa luta por 20 anos. Pior, pensem há vinte anos atrás, nós não tínhamos nem direito à medicação pelo SUS. Nossa demanda daqui há vinte anos vai estar congelada pelo que estamos vivendo hoje?" Ao interrogar uma interlocutora da pesquisa sobre se fariam uma carta de repúdio, como haviam feito semanas anteriores, ela informou que "agora não dá pra ficar escrevendo cartas e esperar. Temos que ir pra rua!”.
\end{abstract}

A emergência de novas demandas e da formalização de ações reflete agenciamentos de atores que são confrontados a mundos [...] e, "sobretudo, dispõem de uma capacidade de julgamento estético, moral e político" (CEFAI, 2009, p. 15).

À medida que estas ações sociais são enveredadas na busca por políticas públicas, as demandas acionadas tornam-se objeto de ampla tensão, articulação e negociação conforme os modos de produção de "enquadramentos". A demanda por direitos adquire força pela capacidade de articulação que os atores produzem nas relações e disputas dentro dos movimentos sociais e, posteriormente, para com as instâncias do Estado (PISCITELLI, 2016).

Ao ser mencionado na citação inicial que o ativismo (e suas pautas) "independe de sexo, sexualidade, raça, cor da pele, nível social” etc., o que se intentava era dirimir pautas consi-

12 Para acesso ao processo de tramitação deste Projeto de Emenda Constitucional, acessar: https://www25.senado. leg.br/web/atividade/materias/-/materia/127337. Acesso em: 12 jun. 2020. 
deradas fora do escopo restrito do que se entende como "luta em HIV/Aids". Atenuavam-se questões em torno de demandas interseccionadas em HIV/aids como algo de menor valor ou significado político. Em uma das interações entre os presentes no contexto desta citação, e em concordância com essa, foi feita a fala de que "a aids afeta a todos nós". E, por isso, "nossa pauta precisa continuar sendo a que deu certo nos anos 80 e 90 ”.

Os conflitos geracionais, que também implicam reconhecer (ou não) a intersecção de questões sobre classe, raça, gênero e sexualidade e outros marcadores sociais, incidem na forma como passam a ser rascunhados novos enquadramentos políticos e a percepção da legitimação destes na função de demanda coletiva.

O atual cenário social brasileiro, pós-golpe de 2016, vem se mostrando, cada vez mais, cerceado para movimentos sociais e direitos coletivos já adquiridos. A moralidade que se perpetua sobre modos de infecção pelo HIV, o estigma sobre a Aids e pessoas a esta relacionadas têm sido alvo de mobilização contraofensiva pela ascensão de um discurso de extrema-direita.

Esta percepção permeia as discussões que definem pautas e ações sociais no interior do movimento social. Contribui para tornar ainda mais tensionadas as relações que se estabelecem ao complexificar novas emergências públicas de quem vive com HIV/Aids, a partir de uma nova concepção geracional.

Não considero, mediante a isto, que o sentimento vanguarda de um grupo que vivenciou aquele contexto político e obteve êxito ao que politizavam configura-se como aceitação apassivada mediante ao novo cenário. Ao contrário, ressalto os modos de engajamento que produzem diferentes estratégias de agenciamento nas ações coletivas, como resultado das posicionalidades interseccionais e temporalmente vivenciadas por estes sujeitos.

É certo que são distintas as subjetividades que compreendem a perspectiva sobre o ativismo. Há que se destacar, na política de Aids, um contexto inicial marcado pela escassez de políticas e outro, mais recente, de ampliação e fortalecimento da resposta brasileira à epidemia do HIV/Aids. A "iniciação" no ativismo de Aids, cujas formas de participação social diferenciaram-se substanciosamente nestes cenários, despontou na controvérsia sobre qual passaria a ser a relação do movimento social com os agentes do Estado, neste novo contexto. Tal como a polarização identificada por Carvalho e Carrara (2015), no movimento trans, a partir da produção de uma nova geração militante, foram sustentadas concepções que defendiam a "necessária busca para sensibilização e amparo do Estado" e, em oposição, uma "ruptura no diálogo, com atos de protesto e denúncia”.

Fatores biomédicos e tecnológicos e as recentes modificações nas políticas identitárias também impactaram no que foi definido como apropriado para a "continuidade" do que já foi 
feito, com forte crítica ao uso da internet como espaço de ativismo. Sobretudo em relação à intersecção entre Aids e outros marcadores sociais, construir e legitimar esta nova agenda requer o esforço de produzir novos enquadramentos interpretativos que perpassam as diferenciações interseccionais.

A filósofa feminista Judith Butler $(2011,2015)$, ao retratar analiticamente sobre a noção de "enquadramento", acentua que são as perspectivas interpretativas sobre os fenômenos sociais que vão implicar a expressão de sentimentos morais, como o horror, a indignação e a comoção, por exemplo. No cenário de guerra, por ela analisado, propõe-se pensar "quais são as condições sociais e os enquadramentos interpretativos duradouros que tornam o horror possível diante de certos tipos de violência, e quando e onde ele é 'descartado' como resposta afetiva disponível diante de outros tipos de violência?” (BUTLER, 2015, p. 227).

Ao propor a consideração acerca da noção de enquadramento, Butler (idem) procura evidenciar o modo em que a vida só é apreendida dentro de certas molduras, que se configuram como operações de poder. A isso, somam-se os processos normativos que são estabelecidos, produzindo-se ou tornando-se aceitáveis. Mas, nessa mesma lógica, operada sob formas de disputas e reprodutibilidade, ao mesmo tempo em que aceita novas formas normativas, colocam-se tantas outras em xeque. É este caráter conflitivo que põe em debate as discussões sobre as demandas políticas das ações sociais dos grupos segmentados que compõe o movimento em HIV/Aids.

Relacionando tal discussão à de Butler (2015), interessa aqui pensar nos enquadramentos operados pelas lógicas de poder do Estado, sem tomar como perspectiva uma consideração essencialista. De acordo com a crítica de Butler (idem), a questão não é preconizar a alocação do poder do Estado no cerne do debate, tampouco desconsiderar que os usos feitos por este se dão a partir tanto da produção quanto da pressuposição de suas próprias operações de poder. Cabe considerar que processos são erigidos a fim de que certos enquadramentos passem a ser aceitos nos padrões normativos do Estado.

Como, na tensão entre processos de alocação x exclusão de enquadramento, sujeitos "negociam" direitos? Dado ao fator social estigmatizante vinculado às Pessoas Vivendo com HIV/Aids, como são elaborados e definidos os regimes de visibilidade ativista?

A PEC n. 55/2016 passou a ser percebida e tomada como objeto de "intervenção" pelos participantes da rede de jovens e como algo que impacta diretamente nos direitos à saúde desta geração e na interlocução com outros coletivos do movimento HIV/Aids do estado do Rio de Janeiro. O modo de percepção dessa PEC colabora em problematizar as questões anteriores.

Todas as propostas apostavam na sensibilização de atores públicos ou da sociedade para 
que compreendessem os efeitos desta medida para o país e, sobretudo, para usuários das políticas de saúde que seriam afetadas pelo que nomearam como "desmonte do SUS". Há diferentes possibilidades de alcance e de estratégias contidas nestas, conforme destaco a seguir.

A proposta inicial de intervenção por meio da elaboração de carta de repúdio foi percebida como pouco ou nada produtiva. Chegou-se a rascunhar-se um roteiro e sugeri-lo como documento-base para um possível diálogo com "representantes 'da causa" e líderes partidários na Câmara e no Senado.

A possibilidade de utilização da internet como instrumento de visibilização foi desincentivada por não apresentar resultados "concretos" sobre os quais se poderia dimensionar. Passou-se a considerá-la como um espaço não-legítimo de ativismo, que punha em xeque o resguardo pessoal da identidade, um cenário que iniciava incertezas sobre o tratamento a sujeitos moralizados como "vítimas culpáveis" (LACERDA, 2006).

Esse debate levou à decisão por "métodos de ativismo efetivo", com dois momentos diferentes. $\mathrm{O}$ encontro foi marcado para o dia $1^{\circ}$ de dezembro de 2016, Dia Mundial de Luta contra a Aids, e teve como espaço destinado para a "intervenção” a Praça Mauá, na zona portuária do Rio de Janeiro. A escolha almejava alertar os diferentes sujeitos sociais que passam ou utilizam daquele espaço para momentos de sociabilidade e provocar à sensibilização para a não aprovação da PEC n. 55/241 que, naquele momento, já estava para votação na etapa final, pelo Senado.

O primeiro momento ocupou a maior parte do tempo e foi dedicado à confecção de cartazes, intervenções com transeuntes, palavras de ordem no microfone e um abraço simbólico entre os ativistas que estavam identificados por uma camisa preta com letras vermelhas que estampava a palavra "Vivendo". No segundo momento, circulou-se em torno da Praça Mauá, com os cartazes, palavras de ordem, apitos e bolas brancas. A passagem foi performada pelo conjunto do que se apresentava: pessoas andando de blusa preta com letras vermelhas, cartazes com palavras "SUS", "Aids", "Viver"/”Vida", "Prevenção", "Estigma”, "Saúde”, "Governo" etc. e pelo uso da frase "O SUSpira, mas não morre!”, cuja sentença era iniciada pelo grupo que estava à frente e era seguida pelos que vinham "na linha de trás".

Ao uso do microfone, denunciavam a ausência da escuta da sociedade civil para avaliar os impactos da PEC n. 55/2016 e como ela afetaria diferencialmente as pessoas que estavam presentes ali. A proposição de negociação entre atores do movimento social e dos agentes do Estado produz efeitos sobre a própria política destes sujeitos. Ao se tornarem "objeto de ação governamental, acabam por se redefinir" (SOUZA LIMA, 2002, p. 18), incide-se em um processo permanente de questionamentos dos serviços públicos, que os imiscui e induz à transfor- 
mação.

A não politização de questões tidas como externas ao repertório da intervenção proposta, na intenção de "visibilizar uma causa que é de todos nós", atenta ao fato de que o reconhecimento e a legitimação de pautas fazem parte de um processo complexo e permeado por disputas de agenciamento social. O "apagamento" desta questão, contudo, provocou novos incômodos, na medida em que os jovens presentes - seguidos pelos que vêm se dedicando à introdução da pauta raciais, de classe e feminista - manifestaram sentir-se silenciados pelos demais segmentos ali presentes pelo direcionamento dado ao que "seria indicado" para os cartazes e palavras de ordem.

Em reunião subsequente, decidiram que precisavam ocupar outros espaços, principalmente no "subúrbio da cidade". Além da busca para que suas demandas se tornem passíveis de serem reconhecíveis como "questão do Estado" (cf. VIANNA; FARIAS, 2011; LACERDA, 2015; FERREIRA, 2016), visavam a diversificar o público que acessava estas informações. A medida se ancorava na concepção de que a emergência das experiências sociais "apagadas", que representa só "números frios", não produziria os efeitos necessários para a reconstrução de políticas públicas (MALUF, 2010).

\section{TENSÕES EM TORNO DA ELABORAÇÃO DE UMA POLÍTICA}

Conforme apresentado, a articulação interna de demandas se dá por meio de negociações sobre certos modelos de um enquadramento coletivo que, como tal, represente a "todos". Como resultado, torna-se objeto de disputas a forma como a visibilização de uma pauta tornada legítima produz, necessariamente, o apagamento de outras e suas possíveis consequências. É notória a preocupação com as ações que têm sido operacionalizadas "para fora", como instrumentos de intervenção política.

A noção de visibilidade, trazida para compreender este fenômeno, tem sido recorrente em movimentos sociais, como o movimento LGBT, feminista e negro. Essa noção tem sido empregada como forma de enfrentamento ao alijamento social ao qual sujeitos são imputados, por exemplo, em virtude da heteronormatividade (cf. BUTLER, 2003). A referida noção também foi utilizada, no contexto apresentado, como categoria êmica para evidenciar o processo de disputas pela legitimação de pautas e estratégias que ocorreram internamente e na relação com o Estado. 
Em termos analíticos, um dos textos mais expressivos, nesta discussão, é o de Michael Pollak (1985). O autor debruça sua análise sobre o processo de coming out como um reconhecimento público da sexualidade divergente, não heterossexual. Como tal, o coming out é construído no indivíduo ao longo do tempo e a partir de um conjunto de ações, que variam desde a participação em espaços de sociabilidade homossexual ao enfrentamento da homofobia ${ }^{13}$. A noção de visibilidade tende a refletir sobre a dimensão de tornar visível uma "causa" de dimensão coletiva, burlando as fronteiras ante à norma.

Miskolci (2014, p. 62), em sua pesquisa sobre a negociação da visibilidade na esfera da sexualidade de forma comparada entre Brasil e EUA, definiu que

Um regime de visibilidade traduz uma relação de poder sofisticada, pois não se baseia em proibições diretas, antes em formas indiretas, mas altamente eficientes, de gestão do que é visível e aceitável na vida cotidiana. Assim, um regime de visibilidade é também um regime de conhecimento, pois o que é visível e reconhecido tende a estabelecer as fronteiras do pensável.

É importante assinalar que tornar visível a "causa" em torno do HIV/Aids conformaria uma espécie de enunciação (GOFFMAN, 2008). Apesar de expor o sujeito ao estigma ao qual está relacionado, paradoxalmente lhe proporcionaria a retirada de uma posição inferiorizada, a partir da ação protagonista. Essa controvérsia sugere a construção de diferentes regimes de visibilidade mais ou menos reconhecível.

A reprodução do "desabafo" e sua relação com medidas iniciais em torno da PEC n. 55/2016 revelam as contradições de gerenciar uma "identidade indizível" (POLLAK, 1990). As consequentes disputas sobre diferentes regimes de visibilidade e legitimação de novas pautas são reflexos de agenciamentos em relação à permanência e sofisticação dos efeitos moralizantes ${ }^{14}$ (SONTAG, 1989) sobre o HIV, à Aids e aos sujeitos a estes relacionados ${ }^{15}$. Apresentam-se

13 Partindo de uma perspectiva crítica feminista, pude atentar-me em outro contexto $(2014,2015)$ à forma como a busca pelo reconhecimento do Estado (resultado de discursos e práticas diversas operacionalizados sob a noção da visibilidade pelo atual movimento LGBT) corroborou para a adequação e normatização dos homossexuais, que refletiu na produção do sujeito "homoafetivo".

14 Um caso exemplar se refere ao que tem ocorrido na rede acerca da pedagogização da maternidade de jovens mulheres vivendo com HIV/Aids indetectáveis. Partindo de narrativas públicas destas mulheres, que apresentam um motivo considerado aceitável e temporalidades precisas para a retirada da camisinha nas relações sexuais com seus companheiros, tem sido reiterado um valor moral no que se refere ao gerenciamento das escolhas preventivas de pessoas vivendo. Isso ocorre, por exemplo, quando outros jovens pertencentes à rede tomam a própria indetectabilidade como estratégia preventiva a ser associada ou não ao uso da camisinha e balizam esta escolha em relação à satisfação pelo prazer sexual ( $c f$. COITINHO FILHO; RINALDI, 2021).

15 Já ouvi comentários sobre pessoas que foram expulsas de comunidades dominadas pelo tráfico do Rio de Ja- 
atualmente segundo representações vigentes e novas gramáticas ${ }^{16}$.

A elaboração e utilização de regimes de visibilidade varia em termos históricos, sociais e políticos e conforme a construção de perspectivas próprias sobre viver com HIV/Aids e do que é entendido como ativismo. Os regimes de visibilidade se reposicionam em relação a noções, sentidos e moralidades em torno do seu próprio "eu”. Essa redefinição de si, conforme mostra o trecho de uma entrevista a seguir, denota a fluidez desta identidade.

_ Muitas vezes eu precisava sair de casa, encontrar com algumas pessoas lá do movimento [social] e falar qualquer coisa. Não precisava ser sobre HIV, não. Pesquisador: Em qual ano?

- Isso lá pros anos 2000, mais ou menos. Mas, eu sabia que ali eu era eu mesmo. Não estava tendo que me esconder sobre uma parte de mim que minha família nunca vai poder saber. É muito difícil assumir ser gay com HIV, porque é duplamente estigmatizado. Mais ainda, é como se você não pudesse fugir da opção que lhe espera, enquanto gay.

Pesquisador: E como você articulava essa identidade em diferentes espaços?

_ No trabalho, com a família e alguns relacionamentos menos importantes que tive, eu não falava neste assunto. Jamais! Quando isso ficava muito engasgado, eu encontrava com o pessoal, como eu te falei. A gente ia pro bar, na casa de alguém, qualquer coisa. Mas, a gente precisava ter um momento que a gente não precisasse ficar se preocupando em cometer algum "deslize" [faz o gesto de aspas na mão].

Pesquisador: E como esta identidade se refletia no movimento social?

_ Olha, eu nunca pude mostrar quem eu era. Tive pessoas que deram entrevistas e até perderam o emprego. A gente sabe que ainda tem gente que pensa que vai pegar aids se utilizar o mesmo talher. Isso é muito real! Mas, eu sempre apoiei e incentivei quem ia pras ruas.

Pesquisador: E como você apoiava, para além do incentivo?

Eu participava das reuniões, eu ficava me atualizando das informações, ouvia e conversava com a galera lá do grupo. Vou te confessar que sou fã dessas pessoas que deram as caras na rua. Graças a esses é que temos nossos direitos hoje! (Cadernos de campo: entrevista realizada em novembro de 2016).

A gestão da identidade sorológica gerou impactos no modo como, na constituição de identidades coletivas, a busca pelo reconhecimento de demandas pela legitimação do Estado

neiro devido à descoberta da sorologia. Essa questão, no entanto, é sempre evitada, falada em circunstâncias bem específicas e entre pessoas mais próximas.

16 Bastos (2002) indica que, numa busca por vítimas e culpados, homossexuais e usuários de drogas injetáveis foram diretamente associados ao contágio e transmissão da doença, por já representarem grupos estigmatizados. Nos Estados Unidos e Europa, o "estilo de vida gay" foi logo condenado, na associação entre homossexualidade e AIDS, definindo-a como "câncer gay" ou "praga gay" (DANIEL; PARKER, 1991). É digno de nota destacar a culpabilização dos homossexuais como decorrente das ideias de transgressão da sexualidade, no contexto da liberação sexual da década de 1970 . 
tem exigido que os movimentos sociais visibilizem a sua "causa"17. Tal proposição nos leva à seguinte questão: como diferentes regimes de visibilidade produzem sentidos e tornam-se mais ou menos legitimados entre participantes do ativismo em HIV/Aids?

As ações projetadas pelos jovens da rede referentes a práticas de ativismo são constituídas por uma ampla variabilidade. Tais ações são, sobretudo, reflexo do modo como os sujeitos valoram, regulam e conduzem a identidade sorológica. Isso é algo que, como demonstrado no trecho anterior, reflete uma gestão histórica referente à experiência com HIV/Aids, tanto em termos de mobilização política quanto de vivências cotidianas.

Carvalho (2015) e Carvalho e Carrara (2015) apresentam dados, a partir da reivindicação por visibilidade e reconhecimento no ativismo trans no Brasil, universo que também é marcado por estigmas e produto de distintos campos discursivos. Dentre outras questões, duas apresentam importante relação com a presente discussão.

Os autores destacam que diferentes regimes de visibilidade são produzidos conforme algo é tornado visível. A exposição de corpos de travestis mortas difere da visibilidade provocada pela exibição de corpos femininos em um programa que propõe identificar, a despeito da aparência, qual das representantes não seria uma "mulher de verdade". Evidenciam também que os regimes de visibilidade podem assumir coexistências estratégias, conforme objetivos e relações estabelecidos. Posições tidas como "mais defensivas" ou "mais radicais" são utilizadas nas arenas de luta política diferencialmente, definidas a partir do alcance almejado pela ação.

A visibilização projetada pelo ativismo é relacionada a outras esferas discursivas advindas de noções biomédicas, políticas sociais, jurídicas, religiosas, morais etc. Isso faz com que diferentes regimes de visibilidade fabriquem conhecimentos sobre os direitos à saúde das Pessoas Vivendo com HIV/Aids e à atribuição do Estado. A concorrência entre estas, a partir do contexto aqui apresentado, atribuem diferentes visibilidades na qual estes sujeitos se configuram como objetos de políticas públicas. Na atual conjuntura política, o estigma é acionado como valor determinante e, por isso, mediador na elaboração das estratégias de visibilidade.

17 É importante considerar também na forma como, na relação entre movimento social x Estado, algumas identidades políticas e de saúde são "negociadas", tornadas como alvo de disputas. Podemos mencionar, por exemplo, a atual noção acerca da identidade "indetectável" e o modo como tem sido percebida com certo temor por instâncias de saúde no modo como os indivíduos vão fazer do uso de seus corpos e sexualidade, quando esta é entendida como condição ideal de vivência da sorologia na relação entre células de CD4/CD8 e carga viral. Alguns estudos recentes têm apontado que essa condição ideal tem implicado recontaminação por troca de cepas do HIV, taxas elevadas de ISTs (anteriormente denominadas DSTs) e novas infecções para HIV, relacionadas a práticas sexuais sem preservativo. A tensão em torno dessa questão gira em torno do que problematiza Maluf (2010, p. 29): "até que ponto a utilização de uma categoria médica significa a adoção dos mesmos sentidos dados a esta pelo campo biomédico e científico?". No entanto, ainda que não recobremos tal questão agora, podemos ilustrar o modo, por exemplo, como certas identidades são construídas e "negociadas" com agências de saúde. 
Numa perspectiva mais ampla, que apresenta o cenário social brasileiro, a questão da identidade associada à sorologia tem sido ainda mais tensionada, permeada por medo e riscos. Isso tem se dado devido ao retorno da discussão em torno do Projeto de Lei (PL) nº 198/2015 ${ }^{18}$, que criminaliza o sujeito transmissor do vírus HIV. Tal projeto, operado por um idioma criminal, ao invés da seara da saúde pública, reforça ainda mais o estigma da culpa e da precaução ao "portador do vírus".

Mais recentemente, a fala do presidente da república, Jair Bolsonaro - eleito em 2018 pelo Partido Social Liberal (PSL), mas atualmente sem partido - caracterizou que "pessoa com HIV é uma despesa para todos"19. Nesta oportunidade, além de reforçar a ideia de culpa e "responsabilidade" sobre a própria condição sorológica, também denotou algumas representações estigmatizantes. Mais ainda, considerando o alcance e os efeitos da fala de um chefe de Estado, muitos interlocutores da pesquisa se manifestaram indignados com a repercussão negativa. Comentários em redes sociais reforçavam a ideia de que Pessoas Vivendo com HIV/ Aids eram culpadas pela sorologia. Esse advento reforçou a preocupação com as medidas que passariam a ser adotadas pelo governo de Jair Bolsonaro sobre o custeio do tratamento e a integridade física destes sujeitos.

$\mathrm{Na}$ minha pesquisa de doutoramento, além da etnografia na Rede Jovens Rio+, realizei 14 entrevistas em profundidade. Numa das questões, em que buscava identificar emoções relativas ao experienciar o HIV, na condição indetectável, fui surpreendido pela relação de o "medo" aparecer mais vinculado às incertezas sobre a garantia do tratamento pelo atual governo do que pela eficácia desse para a garantia de saúde.

Voltando ao contexto de discussão sobre os efeitos da PEC n. 55/2016 para o ativismo em HIV/Aids, foram-se relatados os desafios de modificar pautas e estratégias de ações. Em uma conversa informal com importante interlocutor da pesquisa, um jovem que se identifica a partir da atuação em ações interseccionadas entre HIV/Aids e racismo, desigualdades de classe e homossexualidade, foi destacada a necessidade de maior alcance do número de pessoas e da diversidade que representam. Como exemplo de sua fala, mencionou-se a necessidade de reposicionar as atividades para além da região central do Rio de Janeiro. Ele pressupõe que esta permanência reitera privilégios de homens gays, brancos, que têm trabalho formal e geralmente frequentam um perfil socioeconômico de espaços de sociabilidade em comum. "Saber as for-

18 Para visualização da tramitação do Projeto de Lei no 198/2015, ver: https://www.camara.leg.br/proposicoesWeb/ fichadetramitacao?idProposicao=945940. Acesso em: 16 fev. 2020.

19 A matéria completa pode ser acessada em: https://oglobo.globo.com/sociedade/pessoa-com-hiv-uma-despesa-para-todos-diz-bolsonaro-24231125. Acesso em: 16 fev. 2020. 
mas de prevenção que não seja só a camisinha e que possa proporcionar mais prazer no sexo ainda é um privilégio do gay branco de classe média."

Essa questão central que ele traz, para além da importância do conteúdo em si, contribui para indicar o reposicionamento das estratégias. A ocupação de espaços anteriormente invisibilizados passa a garantir o acesso a pessoas e suas respectivas pautas, anteriormente não legitimadas pelo ativismo. A sensibilização para este reordenamento interno atentava sobre a produção de novas visibilidades, do que se espera tornar visível. Algumas das questões que passaram a compor o léxico ativista foram: narrativas sobre saúde mental da Pessoa Vivendo com HIV/Aids em contexto de pobreza/desemprego e violência; vulnerabilidade e paradigmas no acesso aos serviços de saúde por jovens mulheres bissexuais; enfrentamento da homofobia e sorofobia familiar.

Os conflitos em torno desta temática convergem a partir de uma disputa que se mostra, sobremaneira, de caráter geracional. Neste aspecto, os conceitos sobre "jovem"/“juventude", eram utilizados no contexto mais amplo do ativismo como categoria de acusação. Mais do que se referir a uma etapa da vida, traz-se como panorama a ideia de que a mudança organizacional e efetividade do ativismo foram modificadas pelo fato de os atuais sujeitos não terem vivenciado o início da epidemia de Aids.

\begin{abstract}
Antigamente a gente ia pra rua, dialogava direto com o governo. Conseguimos que vocês hoje não precisem lutar pra ter remédios e não morrer. Mas hoje a galera, sobretudo a juventude, não está nem aí, mal querem tomar o remédio. Cadê eles aqui agora? Será que não estão fazendo um tour-AIDS? Por isso, que vamos ter que engolir a PEC n. 55/241 e teremos um grande retrocesso. Ninguém mais sai e dá a cara, e luta, e exige os direitos. Dar a cara é sim a luta. Ficam se escondendo com medo disso e daquilo e depois, quando não tiverem mais nem medicamento, vão valorizar o que a gente vem falando há muito tempo: o movimento HIV/Aids se perdeu, ele não luta mais. A gente vem, troca histórias, mas e aí? (Cadernos de campo: Rio de Janeiro, dezembro de 2016).
\end{abstract}

A narrativa anterior foi proferida em um momento de organização da campanha de $1^{\circ}$ de dezembro de 2016 - Dia Mundial de Luta contra a Aids. Diferentemente do que venho observando desde 2014, quando ingressei neste campo de pesquisa, os ânimos se acirraram entre os diversos coletivos ali presentes. Embora houvesse a representação de diferentes segmentos, como o de mulheres, grupos LGBTQI+, população Trans+ etc., a discussão enveredava pela oposição dicotômica em relação aos jovens e o que se compreende como relacionado a cultura juvenil.

O conteúdo apresentado gerou uma disputa em torno dos significados que o ativismo 
tem e da forma como a relação que constitui com o Estado reflete na conquista de direitos. Mas, ao canto da sala, onde eu estava, muitas pessoas criticavam a fala anterior, mencionando que “dar a cara para falar sobre Aids não é fácil, porque as pessoas ainda associam a Aids a algo ruim ou perigoso" ou que "cada um tem o seu tempo para chegar ao ativismo da forma como melhor for, temos que ter paciência e entender que uns escolhem uma forma e outros escolhem outra".

Como forma de promover o reconhecimento das pautas do ativismo, muitos jovens da rede têm se utilizado e difundido a noção de que "não é preciso ter HIV para falar de HIV". Esta forma de engajamento político está presente em outros movimentos sociais, como os dedicados a pautas raciais e relativas à diversidade sexual. No ativismo da Aids, apresenta significado particular. É uma forma potencialmente desestabilizadora dos "riscos" associados ao estigma da identidade das pessoas vivendo. Segundo a concepção local, a utilização desta noção atende à necessidade de visibilização da temática da Aids, borrando possíveis associações entre os enunciantes e o diagnóstico.

A insistência de muitos jovens nessa "estratégia" tem sido apreendida pela ideia de que "somente a informação cura". E que este seria "o caminho" para mobilização das ações de educação em saúde sexual e reprodutiva associada à prevenção e/ou promoção de saúde. Por isso, temáticas em torno do uso correto do preservativo, identificação de ISTs ${ }^{20} / A I D S$, prevenção combinada, gravidez, vulnerabilidade associada a identidades sexuais e de gênero, entre outras têm sido abordadas em ações coletivas, ampliando e aprofundando o escopo temático.

Também tem sido feitas menções a artistas que participam de campanhas nacionais sobre a temática e participantes do movimento social que não têm status soropositivo. No Rio de Janeiro, há significativa evidência sobre a atuação de uma médica infectologista e de uma ativista em Direitos Humanos na saúde como sujeitos exemplares. Relacionada à estratégia anterior, nesta é também ilustrativa a possível desvinculação entre ativismo em HIV/Aids e status soropositivo.

Outra importante interlocutora da pesquisa, ao retratar o ressurgimento da lei que prevê criminalizar o transmissor do vírus HIV, falou de modo informal que se arrependeu de ter exposto sua imagem para falar sobre o diagnóstico. Ela menciona que, apesar de a sua fala ter sido ovacionada entre seus pares, não acredita que tenha tido repercussão suficiente fora daquele espaço. Ela acrescentou que, para além daquele momento, não houve melhor aprovei-

20 ISTs é a sigla para Infecções Sexualmente Transmissíveis. É utilizada em substituição à sigla DSTs, que se referia a Doenças Sexualmente Transmissíveis. 
tamento para debater e ampliar as ideias que trazia sobre prevenção entre mulheres de camadas populares. Mediante esta constatação e em razão do atual cenário, ela julga necessário manter a visibilidade sobre as pautas sem necessariamente vincular a imagem das Pessoas que Vivem com HIV/Aids, e diz:

Eu te confesso que hoje eu tenho medo. Quando decidi fazer a entrevista para divulgação na televisão eu estava vivendo um momento em que nossos direitos não eram tidos como um inimigo. Eu me sentia feliz por estar falando aquelas palavras, me imaginava uma ativista que teria o nome na história do movimento de Aids. Mas, quando eu penso em todo esse cenário, na forma como as pessoas estão olhando pra nós e mostrando que elas nunca deixaram de achar que isso é uma consequência irresponsável, com palavras que trazem muita dor, eu preferiria ter cuidado mais de mim. Me sinto um alvo fácil, sabe?

Quando abordada sobre estratégias de prevenção neste contexto atual, ela reforça:

Você já deve ter ouvido alguém falar que hoje se vive com HIV como qualquer outra doença crônica, correto? [Eu aceno que sim com a cabeça]. E você já ouviu alguém ser xingado de diabético ou de hipertenso ou de terem medo de que alguém descobrisse isso? [Eu aceno que não com a cabeça]. É disso que eu estou falando! Se ainda se utiliza do HIV/Aids como forma de ofender ou diminuir alguém, é porque não podemos deixar de compreender que as mudanças na sociedade não foram tantas assim como se pensa.

Mais do que precisar qual estratégia fomentará as ações coletivas, a narrativa anterior denota que os sentidos em torno da visibilidade são estabelecidos de forma tênue e se produz por meio de um fenômeno social dinâmico sobre o qual interagem sujeitos, demandas, contextos, moralidades e racionalidades vigentes.

Recobrando uma perspectiva geracional sobre os modos de se fazer ativismo em HIV/ Aids, não estava perceptível a distinção entre visibilidade de demandas coletivas e visibilidade da identidade social do sujeito. Ambas, ao serem tratadas como sinônimos, impunham limites à definição estratégica de ações sociais do ativismo, enquanto o estigma se ressignificava por meio de novos dispositivos sociais.

Considero que as controvérsias em torno das estratégias da ação social são significadas a partir de dois movimentos que se produzem. Há disputas e conflitos inerentes à produção e circulação de diferentes regimes de visibilidade no interior do movimento. Concomitantemente, operam em relação ao estigma social que permanece vinculado às estratégias de visibilização dos enquadramentos e ações coletivas. 


\section{CONSIDERAÇÕES FINAIS}

O presente trabalho teve como centralidade apresentar as reconfigurações no cenário do ativismo do movimento de HIV/Aids. A análise se deu a partir de alguns eventos relacionados ao avanço da tramitação da $\mathrm{PEC} \mathrm{n}^{0}$ 55/2016, tomando como centralidade algumas tensões decorrentes da pauta de direitos sociais no contexto pós-golpe de 2016.

No decorrer da discussão proposta, evidenciou-se que as diferenças geracionais implicavam a forma como diferencialmente percebiam e atribuíam valor a pautas e ações a serem legitimadas como demandas públicas de caráter coletivo. Neste ínterim, experiências interseccionais tomadas como eixo problematizador na relação entre juventude, sorologia e outros marcadores sociais complexificam uma noção identitária da "Pessoa Vivendo com HIV/Aids" fechada em si mesma e consequentemente uma pauta que, engessada, se proponha "de todos".

No cenário social mais amplo, no qual HIV/Aids ainda é lido sob a ótica da marginalização que a caracterizou ainda nos anos 1980, e que se mantém por meio de novas tecnologias morais, o estigma ainda representa relevante desafio na construção e condução de regimes de visibilidade. Produzido contextualmente, o ativismo em HIV/Aids reflete atualmente os muitos vieses de uma moralidade que persiste em sublocar sujeitos, corpos, fluidos, identidades etc.

\section{REFERÊNCIAS}

1. ABERS, R.; VON BULOW, M. Movimentos sociais na teoria e na prática: como estudar o ativismo através da fronteira entre Estado e sociedade? Sociologias, Porto Alegre, RS, v. 13, n. 28, 2011. Disponível em: https:/www.scielo.br/j/soc/a/ vyJvNFtHTjZvHmJfVsN6tTQ/abstract/?lang=pt. Acesso em: 15 mar. 2020.

2. AGUIÃO, S. R. Fazer-se no "Estado": uma etnografia sobre o processo de constituição dos "LGBT" como sujeitos de direitos no Brasil contemporâneo. Tese (Doutorado em Ciências Sociais) - Universidade Estadual de Campinas, Campinas, 2014.

3. BASTOS, C. Ciência, poder e ação: as respostas à Sida. Lisboa: Imprensa de Ciências Sociais, Universidade de Lisboa, 2002.

4. BRAH, A. Diferença, diversidade, diferenciação. Cadernos Pagu, v. 26, p. 329-76, 2006. Disponível em: https://www.scielo.br/j/cpa/a/ B33FqnvYyTPDGwK8SxCPmhy/?format=pdf\&lang=pt. Acesso em: 15 mar. 2020. 
5. BUTLER, J. Vida precária. Contemporânea, n. 1, p. 13-33, 2011. Disponível em: http://www.contemporanea.ufscar.br/index.php/contemporanea/article/view/18. Acesso em: 13 mar. 2020.

6. BUTLER, J. Quadros de guerra: quando a vida é passível de luto? Rio de Janeiro: Civilização brasileira, 2015.

7. CARVALHO, M. F. L. "Muito prazer, eu existo!": visibilidade e reconhecimento no ativismo de pessoas trans no Brasil. Tese (Doutorado em Saúde Coletiva) - Universidade do Estado do Rio de Janeiro, Rio de Janeiro, 2015.

8. CARVALHO, M. F. L.; CARRARA, S. Ciberativismo trans: considerações sobre uma nova geração militante. Contemporânea: comunicação e cultura, v. 13, n. 2, p. 382 400, 2015. Disponível em: https://periodicos.ufba.br/index.php/contemporaneaposcom/ article/view/13865. Acesso em: 14 mar. 2020.

9. CEFAI, D. Os novos movimentos de protesto em França: a articulação de novas arenas públicas. Revista Crítica de Ciências Sociais, n. 72, p. 129-60, 2005. Disponível em: https://journals.openedition.org/rccs/985. Acesso em: 14 mar. 2020.

10. CEFAI, D. Como nos mobilizamos? A contribuição de uma abordagem pragmatista para a sociologia da ação coletiva. Dilemas, v. 2, n. 4, p. 11-48, 2009. Disponível em: https://revistas.ufrj.br/index.php/dilemas/article/view/7163\#: :text=Este $\% 20$ artigo $\% 20$ analisa $\% 20 \mathrm{a} \% 20$ pertin $\%$ C3\%AAncia,hermen $\%$ C3\%AAuticos\%3B\%202)\%20A\%20 reativa $\% \mathrm{C} 3 \% \mathrm{~A} 7 \% \mathrm{C} 3 \% \mathrm{~A} 3 \mathrm{o} \% 20 \mathrm{da}$. Acesso em: 03 mar. 2020.

11. COITINHO FILHO, R. A. Que ousadia é essa? A adoção "homoafetiva" e seus múltiplos sentidos. Dissertação (Mestrado em Ciências Sociais) - Universidade Federal Rural do Rio de Janeiro, Rio de Janeiro, 2014.

12. COITINHO FILHO, R. A. O lugar do afeto na produção do "homoafetivo": sobre aproximações ao familismo e à aceitabilidade moral. Revista Ártemis, v. 19, p. 168-78, 2015. Disponível em: https://www.periodicos.ufpb.br/ojs2/index.php/artemis/article/ view/26212. Acesso em: 05 mar. 2020.

13. COITINHO FILHO, R. A. Uma "rede" de muitos significados: a positivação pedagógica da "experiência soropositiva". Sexualidad, salud y sociedad, Rio de Janeiro, v. 29, p. 195-214, 2018. Disponível em: https:/www.scielo.br/j/sess/a/6yyKjms8DqQDp6RK j5r35hH/?lang=pt. Acesso em: 15 mar. 2020.

14. COITINHO FILHO, R. A.; RINALDI, A. A. Novos repertórios, velhas moralidades: A maternidade na produção de um "HIV saudável". Teoria e Cultura, v.16, p. 79-94, 2021.

15. CRENSHAW, K. Mapping the Margins: Intersectionality, Identity Politics, and Violence against Women of Color. Stanford Law Review, Stanford, v. 43, p. 1.241-99, 1991.

16. CRENSHAW, K. Documento para o encontro de especialistas em aspectos da 
discriminação racial relativo ao gênero. Revista Estudos Feministas, Florianópolis, SC, v. 10, n. 1, p. 171-88, 2002. Disponível em: https://www.scielo.br/j/ref/a/ mbTpP4SFXPnJZ397j8fSBQQ/abstract/?lang=pt. Acesso em: 15 mar. 2020.

17. CUNHA, C. C. "Jovens vivendo" com HIV/AIDS: (con)formação de sujeitos em meio a um embaraço. Tese (Doutorado em Antropologia Social) - Universidade Federal do Rio de Janeiro, Rio de Janeiro, 2011.

18. CUNHA, C. C. Configurações e reconfigurações do movimento de jovens vivendo com Hiv/Aids no Brasil: identidades e prevenções em jogo. Sexualidad, Salud y Sociedad: Revista Latinoamericana, n. 29, p. 249-312, 2018. Disponível em: https://www.scielo. $\mathrm{br} / \mathrm{j} / \mathrm{sess} / \mathrm{a} /$ Tpnb96KTMRpLrJZ9sD88jng/?lang=pt\&format=html. Acesso em: 17 mar. 2020 .

19. CUNHA, C. C. Modos de fazer sujeito na política de Aids: a gestão de jovens vivendo com HIV/Aids. Século XXI: Revista de Ciências Sociais, v. 4, n. 2, p. 91-132, 2014. Disponível em: https://periodicos.ufsm.br/seculoxxi/article/view/17039. Acesso em: 13 mar. 2020.

20. DANIEL, H.; PARKER, R. AIDS: a terceira epidemia. São Paulo: Iglu, 1991.

21. FERREIRA, L. C. M. Pessoas desaparecidas: uma etnografia para muitas ausências. Rio de Janeiro: Editora UFRJ, 2016.

22. FOUCAULT, M. A governamentalidade. In: FOUCAULT, M. Microfísica do poder. Rio de Janeiro: Graal, 1979.

23. GALVÃO, J. AIDS no Brasil: a agenda de construção de uma epidemia. Rio de Janeiro: ABIA; São Paulo: Ed. 34, 2000.

24. GODBOUT, J. O espírito da dádiva. Rio de Janeiro: Fundação Getúlio Vargas, 1999.

25. GOFFMAN, E. A representação do eu na vida cotidiana. Petrópolis, RJ: Vozes, 1975.

26. GOFFMAN, E. Estigma: notas sobre a manipulação da identidade deteriorada. Rio de Janeiro: LTC, 2008.

27. LACERDA, P. M. Meninos de Altamira: violência, "luta" política e administração pública. Rio de Janeiro: Garamond, 2015.

28. LACERDA, P. M. O drama encenado: assassinatos de gays e travestis na imprensa carioca. Dissertação (Mestrado em Saúde Coletiva) - Universidade do Estado do Rio de Janeiro, Rio de Janeiro, 2006.

29. MALUF, S. W. Gênero, saúde e aflição: políticas públicas, ativismo e experiências sociais. In: MALUF, S. W.; TORNQUIST, C. S. (org.). Gênero, saúde e aflição: abordagens antropológicas. Florianópolis, SC: Letras Contemporâneas, 2010.

30. MAUSS, M. O ensaio sobre o dom. Rio de Janeiro: COSACNAIFY, 2003. 
31. MCCLINTOCK, A. Couro imperial: raça, gênero e sexualidade no embate colonial. Campinas, SP: Editora da Unicamp, 2010.

32. MISKOLCI, R. Negociando visibilidades: segredo e desejo em relações homoeróticas masculinas criadas por mídias digitais. Bagoas: estudos gays: gêneros e sexualidades, v. 8, p. 51-78, 2014. Disponível em: https://www.periodicos.ufrn.br/bagoas/article/ view/6543. Acesso em: 12 mar. 2020.

33. PARKER, R. et al. AAids no Brasil. Rio de Janeiro: Relume Dumará, 1994a.

34. PARKER, R. et al. A construção da solidariedade. Rio de Janeiro: Relume Dumará, 1994b.

35. PARKER, R. et al. Políticas, instituições e Aids: enfrentando a epidemia no Brasil. Rio de Janeiro: Zahar: ABIA, 1997.

36. PEIRANO, M. Etnografia não é método. Horizontes Antropológicos, Porto Alegre, v. 20, n. 42, p. 377-91, 2014. Disponível em: https://www.scielo.br/j/ha/a/ n8ypMvZZ3rJyG3j9QpMyJ9m/?lang=pt. Acesso em: 13 mar. 2020.

37. PISCITELLI, A. Conhecimento antropológico, arenas políticas, gênero e sexualidade. Revista Mundaú, n. 1, p. 73-90, 2016. Disponível em: https://www.seer.ufal.br/index. php/revistamundau/article/view/2437. Acesso em: 12 mar. 2020.

38. PINHEIRO, T. F. Camisinha, homoerotismo e os discursos da prevenção de HIV/ Aids. Tese (Doutorado em Medicina Preventiva) - Universidade de São Paulo, 2015.

39. POLLAK, M. A homossexualidade masculina, ou a felicidade no gueto? In: ARIÉS, P.; BÉJIN, A. (org.). Sexualidades ocidentais: contribuições para a história e para a sociologia da sexualidade. São Paulo: Brasiliense, 1985.

40. POLLAK, M. Os homossexuais e a AIDS: sociologia de uma epidemia. São Paulo: Estação Liberdade, 1990.

41. SONTAG, S. Aids e suas metáforas. São Paulo: Companhia das Letras, 1989.

42. SOUZA LIMA, A. C. Gestar e gerir: estudos para uma antropologia da administração pública no Brasil. Rio de Janeiro: Relume Dumará, 2002.

43. VIANNA, A.; FARIAS, J. A guerra das mães: dor e política em situações de violência institucional. Cadernos Pagu, n. 37, p. 76-116, jul./dez. 2011. Disponível em: https:// www.scielo.br/j/cpa/a/VL8rMW8kJGpHgxBZwWt9bMt/abstract/?lang=pt. Acesso em: 17 mar. 2020.

Doutor em Antropologia pelo Programa de Pós-Graduação em Antropologia da Universidade 
Federal Fluminense, Mestre em Ciências Sociais pelo Programa de Pós-Graduação em Ciências Sociais da Universidade Federal Rural do Rio de Janeiro e Especialista em Gênero e Sexualidade pelo Instituto de Medicina Social da Universidade do Estado do Rio de Janeiro. Graduado em licenciatura em História na Universidade Veiga de Almeida. ID ORCID: https://orcid.org/00000001-8909-7731. E-mail: ricardoacf@id.uff.br. 